\title{
International Protection Policy of World Biological Diversity as the Factor of Sustainable Development of the Territorial Systems
}

\author{
Anatoly Stepanov ${ }^{1, *}$, Yuri Kovalev ${ }^{1}$, Maria Ilyushkina ${ }^{1}$, and Alexander Burnasov ${ }^{1}$ \\ ${ }^{1}$ Ural Federal University, Lenina 51, 620000 Yekaterinburg, Russia
}

\begin{abstract}
The article discusses the evolution of international biodiversity policy in the period from 1992 to 2019 as well as it demonstrates the significance of the global problem of species extinction and describes the structure and main directions of international biodiversity policy. The article presents the features of the negotiation process for the protection and use of the world biodiversity, the complexity of forming a unified global policy. Moreover, it outlines the main stages of development of the mechanisms for biodiversity protection. The main documents of international biodiversity diplomacy such as the Convention on biological diversity, the Cartagena and Nagoya protocols are analysed in the article. The role of groups of states in shaping the agenda of conferences, their positions and interests are also studied.
\end{abstract}

Keywords: biodiversity, species extinction, sustainable development, international policy, Convention on Biological Diversity, Cartagena Protocol, Nagoya Protocol, Aichi agreements.

\section{Introduction}

Our planet biosphere has been evolving for several billion years. During this long period, the Earth's ecological system, which is unique in its biodiversity, has been formed. According to the British scientist D. Lovelock, this close connection of biodiversity with abiotic components allows our planet to maintain a state of dynamic equilibrium, which creates optimal conditions for the prosperity of life on it $[1,40]$. Humanity is an integral part of the biosphere, and human lives depend entirely on its condition. Without the physiological activity of plants, animals, and microorganisms, it is impossible to provide society with clean water, air, and food. The preamble to the Convention on Biological Diversity (CBD) refers to the "enduring value of biological diversity as well as the environmental, genetic, social, economic, scientific, educational, cultural, recreational and aesthetic value of biological diversity and its components" [2]. At the same time, humanity has become the main factor in

\footnotetext{
* Corresponding author: asburnasov@urfu.ru
} 
the disappearance of species that has never been seen in the history of our planet. Its economic activity directly or indirectly destroys natural relations and thus deprives many species of the foundations of their existence. This process is observed in all parts of our planet. According to the World Wide Fund for Nature, the world biological diversity, as shown by the Living Planet Index (LPI), decreased by 60\% between 1970 and 2014 [3,5]. Not only rare and sensitive to small environmental fluctuations, but also plants and animals of modified, cultural landscapes are under threat of extinction. If there were about 30 thousand varieties of cultivated corn in the world 100 years ago, today there are only 12 of them left. Only 6 out of 20 thousand Apple varieties can be found in supermarkets in Europe today [4,9]. In the territories of intense economic activity the processes of extinction of living organisms took an apocalyptic scale. In Germany, for example, the number of birds has decreased by $80 \%$ over the past 200 years, and the biomass of insects has decreased by almost three times in recent years [ibid. 7]. An even more dramatic situation is observed in developing countries, where the processes of "harnessing" nature by man are only gaining momentum.

The problem of progressive extinction of biological species requires the creation of international instruments to protect the biosphere and prevent the extinction of biological species. Since the early 1960 s, this issue has been mentioned in international environmental protection documents. In 1992, at the conference in Rio de Janeiro, representatives of more than 150 countries signed the Convention on Biological Diversity. The preservation of stable ecological systems and natural habitats of species is called the main mechanism for protecting biological diversity [2,1]. The Convention on Biological Diversity was the first fundamental international document that laid the foundation for the international biodiversity diplomacy. Its governing body is the Conference of the Parties (COP). During 1992-2019, fourteen conferences were held where certain steps were taken to implement the international Convention on Biodiversity. At the initiative of Japan, the period from 2011 to 2020 was declared the UN as the decade of biodiversity. The purpose of this article is to consider the main stages of the formation and evolution of international biodiversity diplomacy, to analyse the issues and decisions of the Conferences of the Parties, the structure of the negotiation process, and to characterize the interests of various groups of countries.

The theory of neorealism in international relations (K. Waltz, Grieco D.) and the "multiple streams" framework (Multiple Streams Theory) by the American political scientist D. Kingdom were used as a theoretical basis of the study [5, 6, 7]. According to the neorealist approach, the structure of the international system is anarchic due to the lack of higher authority. The states are defined as integral structures that seek to expand their power. They are the dominant actors in the system of international relations [5]. Motivation of all states is to ensure their own livelihood and maximize the benefits in the political, economic and social spheres. International negotiations on certain topics connected with the protection of world biodiversity (for instance, on Access and Benefit Sharing) demonstrate the pursuit of their own internal interests by states. However, the interaction of states in an effort to expand their capabilities leads to the formation of a certain international regime, in which there are not only absolute, but also relative advantages. Grieco D. emphasizes the efforts of states to obtain relative advantages, which makes international cooperation and the formation of international regimes possible [6,128]. According to the multiple streams framework, three independent political streams are required to form a new political field. These are the problem stream (the public's awareness of the problem), the policy stream (the political system's desire to solve this problem), and the political stream (the political system's ability to solve this problem). When these three streams are joined together (coupling), which happens when the windows of opportunity are opened (policy windows) and with the active participation of political entrepreneurs, the chances of politicians adopting a certain policy are significantly increased $[7,86]$. The correlation of these factors with the degree of political activity of states in this area can be traced using the example of international biodiversity protection policy. 
The methodological basis of this article is formed by a retrospective structural-analytical approach. A discursive analysis of the main documents in this area adopted by the world community in the period 1993-2020 allows us to determine the development course of the policy for the protection of world biodiversity, and assess the impact of various factors in the direction of its evolution. International documents adopted at the Conference of the Parties, as well as scientific works of experts in this field were used as the main sources of this study.

\section{Results and Discussion}

The concept of "biodiversity" was transformed from a purely biological term to a political and legal construct that includes both the natural science component and legal aspects of its protection and use. Biological diversity is defined as "the variability of living organisms from all sources, including terrestrial, marine and other aquatic ecosystems and the ecological complexes they belong to; this concept includes diversity within species, between species, and the diversity of ecosystems" [2,3]. At the same time, biodiversity is not just the unity of all living organisms, but also the diversity within living organisms and the relationships between them $[8,16]$.

The level of biological diversity has regional characteristics. Some regions of the world are distinguished by the richness of species, others by their poverty. The centres of Earth biodiversity lie in the tropical and equatorial zones. These are the rainforests of Central and South America, the mountains of Eastern and Southern Africa, Southeast Asia, Northern Australia, Indonesia, and Papua New Guinea. From the political and administrative point of view, these territories are, in general, developing and underdeveloped countries. On the contrary, the territories of industrialized countries are marked by the poverty of their biodiversity (with the exception of Australia and New Zealand). This fact determines the formation of interest groups in international diplomacy aimed at the protection of biological diversity.

The processes of appearance and disappearance of biological species determine the direction of the biosphere evolution. The number of plant and animal species living today is only $1 \%$ of the previously existing species [8]. Human economic activity is considered to be the main reason for the reduction of biological diversity in the world. Human intervention in natural processes is so great that they speak of a new geological period in the history of the Earth, the anthropocene. The contradictions between the linear growth of production based on the absorption of material and energy resources in the economy and the circulation of substances in nature become a destabilising factor for all planetary systems. Ecosystems are especially sensitive to human influence.

The destruction of natural habitats of biological species by humans forms the "core" of the modern political discourse on biodiversity protection. Due to the expansion of agricultural land, the growth of urbanized territories and the construction of new highways, the natural habitat of biological species is disappearing. A highly illustrative example of the processes of natural habitat extinction is the reducing forest areas. Thus, $80 \%$ of the forest area that covered our planet 8 thousand years ago, today is completely cut down. In 50 countries the forest as a natural ecosystem has completely disappeared over the past 100 years [8].

Table 1. Reduction in forest cover in the world (the period 1980-2010)

\begin{tabular}{|c|c|c|c|}
\hline Region & $\begin{array}{c}\text { Area of the } \\
\text { territory } \\
\text { million ha }\end{array}$ & $\begin{array}{c}\text { Forest area } \\
\text { million ha }\end{array}$ & $\begin{array}{c}\text { Annual change } \\
\text { million ha }\end{array}$ \\
\hline
\end{tabular}




\begin{tabular}{|l|c|c|c|c|c|}
\hline & & $\mathbf{2 0 0 0}$ & $\mathbf{1 9 8 0 - 1 9 9 0}$ & $\mathbf{1 9 9 0 - 2 0 0 0}$ & $\mathbf{2 0 0 0 - 2 0 1 0}$ \\
\hline Africa & 2978 & 650 & $-4,2$ & $-4,0$ & $-3,4$ \\
\hline Asia & 3934 & 745 & $-4,3$ & $-0,6$ & 1.5 \\
\hline Europe & 2260 & 1039 & 0.2 & 0.8 & 0.6 \\
\hline $\begin{array}{l}\text { North and } \\
\text { Central } \\
\text { America }\end{array}$ & 2137 & 549 & $-0,9$ & $-0,2$ & $-0,01$ \\
\hline $\begin{array}{l}\text { South } \\
\text { America }\end{array}$ & 1755 & 886 & $-6,4$ & $-4,2$ & $-3,9$ \\
\hline World & 13064 & 3869 & $-15,7$ & $-8,3$ & $-5,2$ \\
\hline
\end{tabular}

Source: $[9,99]$

Other habitats of biological species, such as freshwater and marine ecosystems, dry and sub-humid lands, islands, and mountainous areas, are being destroyed. Understanding the importance of preserving biological gave rise to modern international diplomacy for the protection and use of natural systems.

\section{Evolution, structure, goals and objectives of international biodiversity policy}

The development of international diplomacy in the field of biodiversity is inextricably linked to the processes of "environmentalization", "greening" and recognition of a global environmental problem existence by the world community. Since the mid-1970s, complex problems of environmental pollution, nature protection and global climate change have moved to the "centre " of international policy. In addition to this, the end of the Cold War and the policy of Detente in international relations have dramatically strengthened the environmental component of international policy. In his book "Earth Manifesto", French social philosopher B. Latour identifies the "ecological attractor" as the main course of development of modern international politics [11]. Biodiversity diplomacy is just one of the areas of global environmental policy.

Negotiations on the creation of international instruments for the protection and use of biodiversity began in 1989 on the UN platform [12,30]. The negotiations resulted in the creation of the Convention on Biological Diversity. At the UN Conference on Environment and Development (UNCED) in Rio de Janeiro (Brazil) in 1992, this Convention was presented to the world community. The same year, more than 150 countries signed it. In December 1993, the Convention has come into force. In general, the very fact of the creation and adoption of this Convention is of great historical significance: "The Convention is one of the most comprehensive and forward-looking legal instruments ever adopted by the community of Nations, and summarizes a new vision of the relationship between humanity and nature" [2]. Article 1 of the Convention defines the objectives of the biodiversity policy such as "conservation of biological diversity, the sustainable use of its components and the fair and equitable sharing of the benefits arising out of the utilization of genetic resources, including by appropriate access to genetic resources and by appropriate transfer of relevant technologies, taking into account all rights over those resources and to technologies, and by appropriate funding"[2,3]. The three main objectives of the biodiversity policy identified in the Convention form its basis. The implementation of the third objective of the Convention - 
the fair and equitable sharing of the benefits arising out of the utilization of genetic resources has proved to be the most difficult and controversial in practice.

Just as in climate diplomacy, the Conference of the Parties becomes the main body of international biodiversity diplomacy. As a rule, it is held, on average, once every two years.

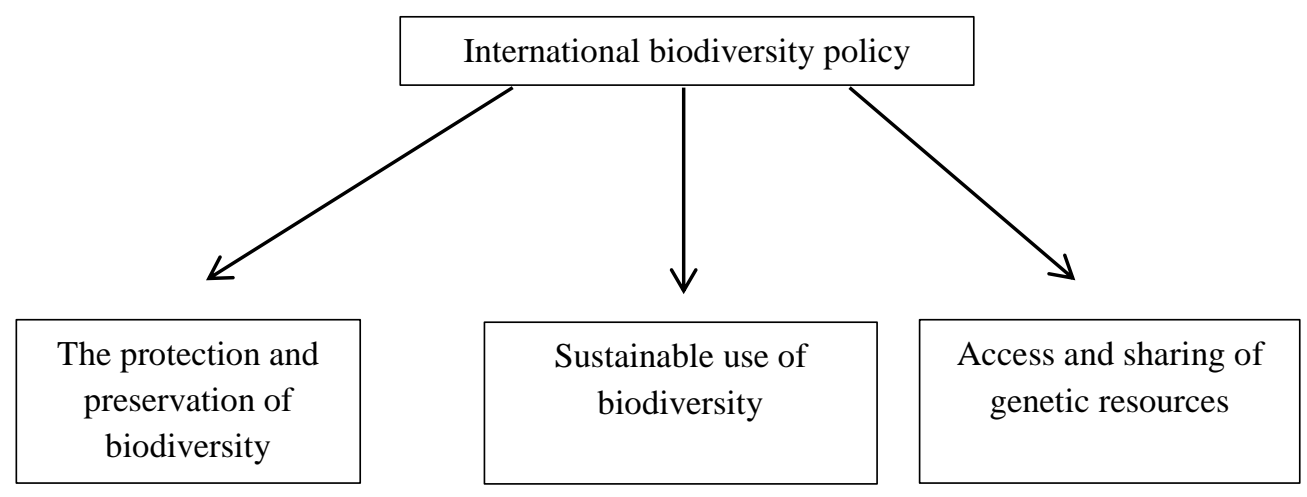

Fig. 1. International biodiversity policy

The first Conference of the Parties (COP) was held from 28 November to 9 December 1994 in the capital of the Bahamas, Nassau. The agenda of the conference mainly consisted of organizational issues related to decision-making procedures and the negotiation process, as well as the issues related to the creation of the Convention Secretariat, funding mechanisms for the programs, etc. At the second Conference of the Parties in 1995 in Jakarta, Indonesia, it was decided to cooperate closely in accordance with the provisions of the CBD, with the World Food Programme (WFP), UNESCO, as well as with the previously adopted Convention on International Trade in Endangered Species of Wild Fauna and Flora (CITES 1973). The results of the first two Conferences of the Parties (COP) showed the effectiveness of this international forum in highlighting new areas of concern within the framework of the Convention on Biodiversity.

In January 2000, an additional agreement to the Convention on Biological Diversity, known as the Cartagena Protocol on Biosafety, was adopted at the meeting of the Conference of the Parties in Cartagena, Colombia. The Cartagena Protocol is intended to protect biological diversity from potential risks posed by living modified organisms and by the use of modern biotechnology. The Protocol confirms the principle of taking precautionary measures and establishes a biosafety mediation mechanism to help exchange information about living modified organisms [13].

The Conferences of the Parties in Curitiba, Brazil (COP 8, 2006) and in Bonn, Germany (COP 9, 2008) were an important stage in the evolution of biodiversity diplomacy. At the conference in Curitiba, positive steps were taken to preserve the biodiversity of island states. For this purpose, a special program was created. It includes the creation of protected island zones, the sustainable use of their biological resources, and their genetic fund [14]. At the conference in Bonn in 2008, the discussion focused on the issues of "biopiracy" and its suppression. The parties agreed that a legal framework should be created in the future for accessing and sharing benefits from the use of genetic resources. If the user countries produce commercial goods from the genetic resources of living organisms from countries that have these resources in their territories, then the countries that supply genetic resources should receive a fair share of sales. It is assumed that the "user" will share the profits with the supplier country. In practice, however, goods production by bio-companies in developed 
countries is not so much related to the access to biogenetic material and biosubstances of supplier countries, but is rather dependent on the access to traditional knowledge of the indigenous population of these countries $[15,53]$. This led to new formidable obstacles in the negotiation process between the states of the world.

In 2010, at the 10th Conference of the Parties in Nagoya, Japan, international biodiversity diplomacy achieved some success. Firstly, The Nagoya Protocol on Access to Genetic Resources and the Fair and Equitable Sharing of Benefits was adopted [16]. The Nagoya Protocol establishes obligations for contracting parties to take measures regarding access to genetic resources and benefit sharing. With regard to the access to the traditional knowledge of indigenous peoples, the Nagoya Protocol provides for the regulation of this issue by the indigenous population itself. The Nagoya Protocol was ratified by most of the world's countries and came into force on October 12, 2014.

Secondly, a revised and updated Strategic Plan for the conservation and sustainable use of biodiversity (Aichi Biodiversity Target) was adopted at the Nagoya conference. The plan was aimed at ensuring that biodiversity conservation structures not only function within the framework of biodiversity-related Conventions, but also throughout The United Nations system and other partners involved in biodiversity management. By July 2019, more than 150 countries had submitted their national strategies and action plans for the conservation of biological diversity until 2020. The Russian Federation presented its strategy in December 2015 (Table 2).

Table 2. Goal-oriented biodiversity strategies and targets until 2020, adopted at the Conference of the Parties in Nagoya in 2010

\begin{tabular}{|l|l|}
\hline \multicolumn{2}{|c|}{ Conference of the Parties in Nagoya in 2010 } \\
\hline $\begin{array}{l}\text { A. Combating the underlying } \\
\text { causes of biodiversity loss by } \\
\text { integrating biodiversity into } \\
\text { government and society action }\end{array}$ & $\begin{array}{l}\text { Goal-oriented targets } \\
\text { aware of the value of biodiversity and the measures } \\
\text { that they can take to conserve and sustainably use it. }\end{array}$ \\
\cline { 2 - 3 } & $\begin{array}{l}\text { 2. By 2020, but no later than this period, the value of } \\
\text { biodiversity is included in national and local } \\
\text { development and poverty reduction strategies and } \\
\text { planning processes and is included, as appropriate, in } \\
\text { national accounting and accounting systems. }\end{array}$ \\
\hline & $\begin{array}{l}\text { 3. By 2020, but no later than this period, incentives, } \\
\text { including subsidies harmful to biodiversity, have been } \\
\text { eliminated, phased out or changed in order to } \\
\text { minimize or prevent negative impacts, and positive } \\
\text { incentives for the conservation and sustainable use of } \\
\text { biodiversity are developed and used in accordance } \\
\text { with and compliance with the Convention and other } \\
\text { relevant international obligations and taking into } \\
\text { account national socio-economic conditions. }\end{array}$ \\
\hline $\begin{array}{l}\text { 4. By 2020, but no later than this period, governments, } \\
\text { businesses and stakeholders at all levels have taken } \\
\text { measures or implemented plans to achieve sustainable } \\
\text { production and consumption and do not allow the } \\
\text { consequences of using natural resources to violate } \\
\text { environmental sustainability. }\end{array}$ \\
\hline $\begin{array}{l}\text { 1. By 2020, the rate of loss of all natural habitats, } \\
\text { including forests, is at least halved, and where feasible, }\end{array}$ \\
\hline
\end{tabular}


B. Reduction of direct pressures on biodiversity and promotion of sustainable use

reduced to almost zero, and degradation and fragmentation significantly reduced.

2. By 2020, the regulation and fishing of all stocks of fish and invertebrates and aquatic plants is carried out stably, legally and using ecosystem-based approaches.

3 . By 2020 , areas occupied by agriculture, aquaculture and forestry should be managed in a sustainable way, ensuring biodiversity conservation.

4. By 2020, environmental pollution, including as a result of excessive nutrient discharges, has been brought to levels at which ecosystem functioning and biodiversity are not compromised.

5. By 2020, invasive alien species and their introduction paths have been identified and prioritized, priority species are regulated or eradicated, and measures are taken to regulate travel routes to prevent their introduction and implantation.

6. By 2015, numerous anthropogenic pressures on coral reefs and other vulnerable ecosystems affected by climate change or ocean acidification are minimized in order to maintain their integrity and functioning.

C. Biodiversity improvement by protecting ecosystems, species and genetic diversity
By 2020, at least 17 percent of land and inland water areas and 10 percent of coastal and marine areas, and in particular areas of particular importance for biodiversity conservation and the provision of ecosystem services, will be maintained through effective and equitable management, the existence of environmentally representative and well interconnected systems of protected areas and the application of other environmental measures on a regional basis and their inclusion in wider terrestrial and marine landscapes.

By 2020, the extinction of known threatened species was prevented, and the status of their conservation, in particular species, the number of which is most reduced, improved and maintained.

By 2020, the genetic diversity of cultivated plants and agricultural and domestic animals and their wild relatives is maintained, including other valuable species from a socio-economic and cultural point of view, and strategies to minimize genetic erosion and preserve their genetic diversity have been developed and implemented.

By 2020, ecosystems that provide essential services, including water-related services, and promote health, livelihoods and well-being, have been restored and 


\section{Increase of benefits for all people provided by biodiversity and ecosystem services}

protected, taking into account the needs of women, indigenous and local communities, and the poor and vulnerable population.

By 2020, ecosystem resilience is enhanced and the contribution of biodiversity to carbon storage is enhanced through conservation and restoration of nature, including restoration of at least 15 percent of degraded ecosystems, which helps mitigate and adapt to climate change and combat desertification.

By 2015, the Nagoya Protocol on Access to Genetic Resources and the fair and equitable sharing of benefits arising from their use had entered into force and was functioning in accordance with national legislation.

E. Improving implementation through community planning, knowledge management and capacity building
By 2015, each Party has developed and has adopted an effective joint and updated national biodiversity strategy and action plan as a political tool and has begun to implement them.

By 2020, the traditional knowledge, innovations and practices of indigenous and local communities relevant to the conservation and sustainable use of biodiversity, and their traditional use of biological resources, are respected in accordance with national legislation and relevant international obligations.

By 2020, knowledge, scientific base and technologies related to biodiversity, its value and functioning, its status and trends in this area, as well as the consequences of its loss, have been improved, widely shared, transferred and applied.

By 2020, but no later than this period, the mobilization of financial resources should significantly expand compared to current levels for the effective implementation of the Strategic Plan for the conservation and sustainable use of biodiversity for 2011-2020 from all sources and in accordance with a generalized and agreed process in Resource Mobilization Strategy

Source: [17, 137-143]

The discussion center of subsequent conferences of the parties (2012, 2014, 2014 and 2018) was formed by issues related to monitoring and evaluating the implementation of national strategies and objectives for the protection of biodiversity. At the last conference in Sharm El Sheikh (November 2018) the preparation of a global framework for biodiversity beyond 2020 was discussed [18]. It is expected that the program will be presented at the Conference of the parties in 2020, which will be held in China. To strengthen the fight against the extinction of biological species, in 2012, the UN established the "Interstate Platform for Biodiversity and Environmental Services". Its main task is to monitor the state of the world ecosystems and form a package of proposals for global political decisions. 


\section{Positions and interests of countries in international biodiversity diplomacy}

The modern mechanism for making international political decisions on almost all the most pressing problems of mankind is a difficult, exhausting process of finding compromises that satisfy the content of the requirements of all parties to the negotiations. Differences in geographical, socio-economic, historical, cultural and technological development between the countries form various national interests aimed at creating positive effects and advantages for their own national structures. The wide range of topics included in the Convention on Biological Diversity makes the negotiation process on these issues extremely difficult, requiring the coordination of interests of not only state actors, but also taking into account the views of other social groups (international government organizations, scientific foundations, indigenous peoples, etc.).

Biotechnology is one of the fastest growing industries in the world economy. The production of new medicines, cosmetics and food is based on the discovery and combination of new biological substances. Some developed countries (Japan, Canada, Australia, New Zealand, and also indirectly the USA) act as a group with common interests in the biodiversity negotiations. These countries are user countries. Their biodiversity policy traces the desire to strengthen their scientific, economic and competitive positions in the world [12, 48]. These countries are focused on the policy of bilateralism in the field of access and use of genetic resources or the creation of such an international regime that would guarantee them unlimited access to the genetic resources of the countries of the South. Especially the United States, which has not acceded to the Convention on Biological Diversity, requires the countries of the South to strictly observe the first and second articles of the CBD, as well as the implementation of the Nagoya Accords [ibid, 49].

A separate group includes the EU countries. Some countries of this group position themselves as the flagships of the process of protecting global biodiversity (Germany, Sweden). Unlike the first group, the EU countries advocated the creation of a mandatory international regime for access to genetic resources and benefit-sharing (ABS mode). The Bonn Guidelines adopted at the 9th Conference of the Parties formed the basis of the Nagoya Protocol. Modern criticism by the EU of international biodiversity diplomacy is aimed at the bureaucracy and complexity of national mechanisms for access to genetic resources and monitoring their use. In the EU itself, there is an increase in disagreement between the member countries of the organization regarding the current policy on the biodiversity protection.

Developing countries (countries of the South) with rich resources have advocated from the very beginning of international biodiversity diplomacy for the creation of a global, legally binding treaty to regulate access to genetic resources and benefit-sharing. Their position is characterized by a specific attitude that is access to their genetic resources is possible only if there is a legal mechanism for sharing benefits. Without benefits for a country, there is no access to their genetic resources [ibid, 51]. The Nagoya Protocol reflects the interests of developing countries. Namibia, Kenya, Madagascar, South Africa are the leaders of the African group with the high activity level. Bolivia has also taken an active stance, which since 1995 has criticized the passive stance of many developing countries on benefit-sharing issues. Developing countries, by the suggestion of Bolivia, should gain access to bioproduction technologies, and not be a bioresource appendage of developed states [ibid, 52]. This requires a global technology transfer program. The Russian Federation occupies a special position in the international diplomacy of biodiversity. Although it is inferior in terms of species diversity to many tropical and subtropical countries, the Russian Federation is on the first place in the world in terms of landscape diversity. At the same time, $65 \%$ of the area of Russia is represented by undisturbed or slightly disturbed landscapes that preserve the natural habitats of plants and animals (this is higher than in the USA, Brazil, Canada, Australia, and other countries). Also, Russia accounts for $20 \%$ of the global forest area. 
Russia ranks first in the world in terms of its contribution to global environmental sustainability [20, 51]. Today, the priority areas of biodiversity policy in the country lie within the development and sustainable functioning of specially protected natural areas, the protection of rare and endangered species of animals and plants, as well as the sustainable use of biological resources (agriculture, forestry, hunting and fisheries) [20, 76]. As in climate policy, in the field of biodiversity, Russia seeks to combine the country's economic growth goals with the environmental challenges of our time.

\section{Conclusion}

Thus, international biodiversity diplomacy is the response of the world community to the global issue of species extinction. Understanding this issue has formed the international biodiversity policy. The Conference of the Parties (COP) within the framework of the Convention on Biological Diversity remains the main international platform for making political decisions on the biodiversity protection. At the same time, international biodiversity policy is a classic multi-level policy. Without the coordinated interaction of the most diverse actors at the global, national, regional and local levels, the implementation of the goals and objectives of the conservation and sustainable use of biodiversity policy is impossible. The effectiveness of international biodiversity diplomacy depends on the degree of cooperation and trust of international actors. The main problem of biodiversity policy is still the existence of contradictions between industrialized and developing countries, as well as insufficient funding for the programs. The elimination of differences between them and the increase in funding for projects to protect natural systems is the only way to preserve the biodiversity of our planet.

\section{References}

1. J. Lovelock, The Revenge of Gaia: Earth's Climate Crisis \& The Fate of Humanity. NY., (2007)

2. Convention on Biological Diversity [Electronic resource] URL:https://www.un.org/ru/documents/decl_conv/conventions/biodiv.shtml (accessed: 12.06.2019)

3. Living Planet Report 2018 [Electronic resource] https://www.wwf.de/living-planetreport/ (accessed: 06.05.2019)

4. T. Bauer, Die Vereindeutigung der Welt. Über den Verlust an Mehrdeutigkeit und Vielfalt. Ditzingen, (2018)

5. K. Waltz, Realism and international politics, New York, (2008)

6. J. Grieco, Anarchy and the limits of cooperation: a realist critique of the newest liberal institutionalism, in: Baldwin, David A: Neorealism and neoliberalism: the contemporary de-bate, New York, NY, 116-142, (1993)

7. J. Kingdon, Agendas, Alternatives and Public Policies. Little, Brown and Company, Boston, (1984)

8. L. Glowka. A Guide to the Convention on Biological Diversity, IUCN Environmental Policy and Law paper. no. 30, 1994 [Electronic resource] URL:https://portals.iucn.org/library/efiles/documents/EPLP-no.030.pdf (accessed: 20.06.2019)

9. S.Engel, Katastrofen-Alarm! Was tun gegen die mutwillige Zerstörung der Einheit von Mensch und Natur? Gelsenkirchen, (2014) 
10. K. Tillman, H. Christoph, Globale Biodiversitätsverluste - es geht um Werte // Jahrbuch Ökologie 2016. Gesucht: Weltumweltpolitik. Stuttgart, (2016)

11. B. Latour, Das terrestrische Manifest. Berlin, (2018)

12. D. Just, Odyssee des Internationalen ABS-Regimes. Eine Analyse struktureller Probleme und asymmetrischer Kräfteverhältnisse//Globale Umweltpolitik und Internationalisierung des Staates (Hrsg. U. Brand). S. 27-74, Münster, (2010)

13. Report on the extraordinary meeting of the conference of the parties to adopt a biosafety protocol to the Convention on Biological Diversity. Conference of the parties to the Convention on Biological Diversity. Cartagena, 2000 [Electronic resource]

URL: https://www.cbd.int/doc/meetings/cop/excop-01/official/excop-01-03-ru.pdf (accessed: 15.06.2019)

14. Report of the eighth meeting of the conference of the parties to the onvention on biological diversity. Curitiba, 2006 [Electronic resource] URL: https://www.cbd.int/doc/meetings/cop/cop-08/official/cop-08-31-ru.pdf (accessed: 16.06.2019)

15. Report of the conference of the parties to the Convention on Biological Diversity on the work of its ninth meeting. Bonn, 2008 [Electronic resource]

URL: $\quad$ https://www.cbd.int/doc/meetings/cop/cop-09/official/cop-09-29-ru.pdf (accessed: 17.06. 2019)

16. About the Nagoya Protocol [Electronic resource]

URL: https://www.cbd.int/abs/about/default.shtml/\#objective (accessed: 22.06.2019)

17. Report of the tenth meeting of the conference of the parties to the Convention on Biological Diversity. Nagoya, 2010 [Electronic resource] URL: https://www.cbd.int/doc/meetings/cop/cop-10/official/cop-10-27-ru.pdf (accessed: 17.06. 2019)

18. Report of the conference of the parties to the Convention on Biological Diversity on the work of its 14th meeting. Sharm El Sheikh, 2014 [Electronic resource]

URL: https://www.cbd.int/conferences/2018/cop-14/documents_(accessed: 18.06.2019)

19. Report of the first meeting of the conference of the parties to the Convention on Biological Diversity. Nassau, 1994 [Electronic resource] URL: https://www.cbd.int/doc/meetings/cop/cop-01/official/cop-01-17-ru.pdf (accessed: 14.06.2019)

20. Strategy and Action Plan for the conservation of biological diversity of the Russian Federation. M., 2014 [Electronic resource]

URL:https://www.cbd.int/doc/world/ru/ru-nbsap-v2-ru.pdf (accessed: 27.06.2019). 